\title{
ASPECTOS ECOLÓGICOS DE EPÍFITAS VASCULARES NA ARBORIZAÇÃO URBANA DE QUINTA DO SOL, PARANÁ, BRASIL
}

\author{
ECOLOGICAL ASPECTS OF VASCULAR EPIPHYTES IN THE URBAN FOREST OF \\ QUINTA DO SOL, PARANÁ, BRAZIL
}

\author{
Gustavo Guazzelli Medeiros Teixeira ${ }^{1}$, Luciano Davi Pretzel ${ }^{1}$, Fernanda Zanela Alves ${ }^{1}$, \\ Marcelo Galeazzi Caxambu²
}

\section{RESUMO}

A arborização é um elemento essencial dentro do planejamento urbano e necessita de uma abordagem florística e ecológica. Assim, o presente trabalho objetivou levantar e a classificar as epífitas vasculares, considerando os aspectos ecológicos da flora presente na cidade de Quinta do Sol, PR, Brasil. Foram analisadas as espécies de epífitas presentes nos forófitos situados no alinhamento urbano, a partir da classificação quanto a origem, síndrome de dispersão e categorias ecológicas. Registrou-se 61 espécies de epífitas vasculares, distribuídas em 21 famílias e 47 gêneros. A família Cactaceae $(21,3 \%)$ e Orchidaceae (18\%) se destacaram como as mais ricas. A categoria ecológica com maior significância foi holoepífita verdadeira e quanto a síndrome de dispersão, houve a predominância de espécies anemocóricas seguidas de zoocóricas. Conclui-se que este estudo apresenta uma das maiores riquezas de epífitas vasculares já encontradas, até o momento, em arborização urbana no Paraná. A ocorrência de algumas espécies está associada a perturbação do ambiente da cidade, ocasionado principalmente pela dispersão realizada pelos munícipes visando a ornamentação. Por conta da maior representatividade de epífitas com dispersão zoocórica, nota-se a necessidade de se estudar ainda mais essa sinúsia no meio urbano, evidenciando a importância da arborização como mantenedora da diversidade faunística.

Palavras-chave: Biodiversidade; Categorias ecológicas; Composição florística; Síndrome de dispersão.

\section{ABSTRACT}

Urban forest is an essential element of urban planning, that needs a floristic and ecological approach. In this way, this study aims to characterize the vascular epiphytic, considering ecological aspects of the flora in the urban area of Quinta do Sol, PR, Brazil. The epiphytes belonging to forophytes located in the urban alignment were analyzed and classified as to the origin, dispersion syndrome and ecological categories. A total of 61 species of vascular epiphytes were recorded, distributed in 21 families and 47 genera. The Cactaceae $(21.3 \%)$ and Orchidaceae $(18 \%)$ were the richest. The most important ecological category was the true holoepiphytes and as for the dispersion syndrome, there was a predominance of anemocoric species followed by zoocoric. In this way, this study presents one of the most rich vascular epiphytes variety already found in Paraná's urban forestry. The occurrence of some species is associated with disturbance of the city, caused mainly by the dispersion carried out by the inhabitants aiming at ornamentation. Because of the greater representativeness of epiphytes with zoocoric dispersion, it is necessary to study this community in the cities, evidencing the importance of the afforestation as a maintainer of the fauna diversity.

Keywords: Biodiversity; Dispersion syndrome; Ecological categories; Floristic composition.

Recebido em 06.07.2017 e aceito em 08.12.2017

1 Graduandos do curso de Engenharia Ambiental. Universidade Tecnológica Federal do Paraná (UTFPR). Campo Mourão/PR.

Email: gustavogmedeiros@hotmail.com; luciano.davi@hotmail.com; zanella.fernanda@gmail.com

2 Engenheiro Florestal. Doutor em Ciências Biológicas. Professor da Universidade Tecnológica Federal do Paraná (UTFPR). Campo Mourão/PR. Email: mgcaxambu@gmail.com 


\section{INTRODUÇÃO}

A arborização é um elemento essencial dentro do planejamento urbano, pois deve ser pensado estrategicamente de forma a integrar o máximo de elementos bióticos e abióticos, visando beneficiar a população, o ambiente e a natureza. Se bem planejada gera uma série de vantagens, como a melhoria do conforto térmico, da qualidade do ar, da saúde psicológica da população, da estética do local, reduz a poluição sonora, fornece ao ecossistema a ciclagem de nutrientes e proporciona alimento e abrigo aos animais (BENZING, 1990; ROSSATO; TSUBOY; FREI, 2008).

A arborização urbana também pode conter sinúsias atreladas a ela, a exemplo das epífitas, que são definidas como plantas que utilizam como suporte para o seu desenvolvimento outras plantas, sem necessitar de seu substrato ou causar prejuízo ao hospedeiro. Caracterizadas pelo estabelecimento de espécies de dossel, as epífitas podem representar até cinquenta por cento do total da flora vascular de florestas neotropicais pluviais (BENZING, 1990).

Estão sendo realizados estudos importantes nas Regiões Sudeste e Sul do Brasil referentes às epífitas em fragmentos florestais, que tratam não só da composição específica, mas também de diversos aspectos ecológicos como síndromes de dispersão e polinização, aspectos fitossociológicos, distribuição vertical, horizontal e ao longo de gradientes latitudinais, entre outros (DETTKE; ORFRINI; MILANEZE-GUTIERRE, 2008).

No estado do Paraná, as pesquisas que abordam a sinúsia epifítica no meio urbano ainda são escassas, a exemplo, têm-se os estudos realizados em remanescentes florestais sob influência da zona urbana em Maringá e Campo Mourão (DETTKE; ORFRINI; MILANEZEGUTIERRE, 2008; GERALDINO; CAXAMBU; SOUZA, 2010) e também os desenvolvidos especificamente na arborização das cidades de Farol e Luiziana (RITTER et al., 2014; DEVENS et al., 2015).

Tendo em vista a importância e carência de pesquisas com epífitas, focadas principalmente na arborização urbana, este trabalho teve como objetivo o levantamento de espécies e aspectos ecológicos como síndrome de dispersão, categorias ecológicas e origem, da flora epifítica vascular presente no alinhamento urbano da cidade de Quinta do Sol, Paraná, Brasil. 


\section{MATERIAL E MÉTODOS}

O presente estudo foi realizado na área urbana da cidade de Quinta do Sol, Paraná, que pertence à mesorregião geográfica Centro Ocidental Paranaense e a microrregião geográfica de Campo Mourão (Figura 1). O município apresenta população de 5.088 habitantes, área de 326,17 km², vias públicas com arborização igual a 90,5\% e urbanização de 22,7\% (IBGE, 2010).

De acordo com Alvares el. al (2013), o clima da região é classificado segundo Köppen como clima subtropical úmido, Cfa, possuindo chuvas durante todo o ano com precipitação anual de 1300 a $1600 \mathrm{~mm}$, apresentando verões quentes com temperatura média anual de 20 a $22{ }^{\circ} \mathrm{C}$.

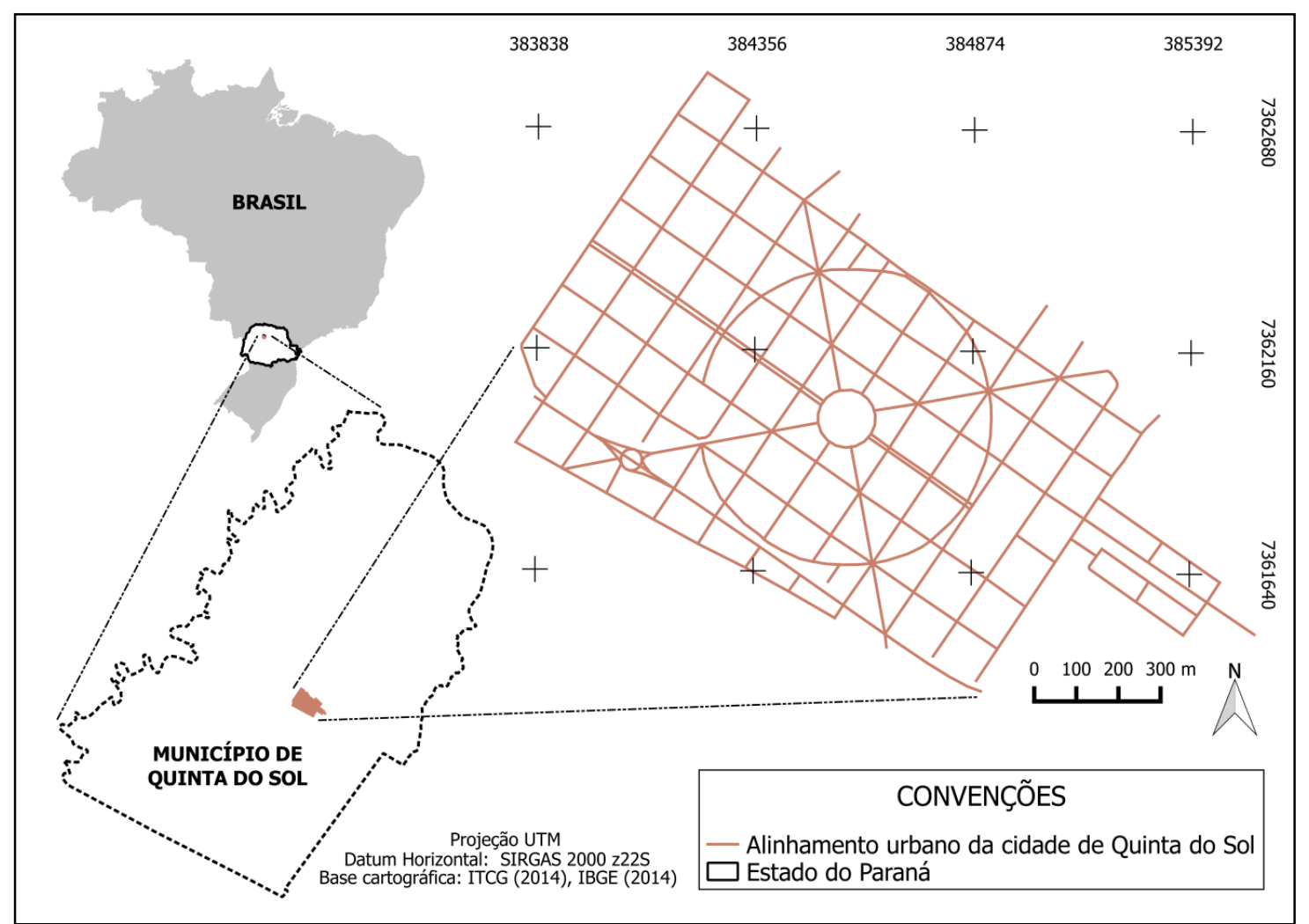

Figura 1. Mapa de localização do município de Quinta do Sol - Paraná, Brasil

Figure 1. Location map of Quinta do Sol municipality in the state of Paraná, Brazil

O levantamento das epífitas presentes no alinhamento urbano da cidade de Quinta do Sol ocorreu nos meses de março a junho de 2017. Para análise dos forófitos foram verificadas as espécies, tanto arbustivas quanto arbóreas, presentes nos canteiros centrais e calçadas de vias públicas, excetuando-se as localizadas no interior de praças, de forma análoga ao feito por Meira et al. (2015). 
Os espécimes de epífitas foram amostrados de acordo com IBGE (2012). O material botânico foi encaminhado para o Herbário da Universidade Tecnológica Federal do Paraná, Câmpus Campo Mourão (HCF), onde foi conduzida a identificação das espécies e a classificação em nativas e exóticas, por meio da comparação com o acervo do HCF e com apoio de bibliografia especializada. A classificação em nível de família botânica seguiu APG IV (2016) para as Angiospermae, e PPG (2016) para as Pteridophyta. A Flora do Brasil 2020 em construção (2017) foi utilizada para os epítetos específicos e seus respectivos autores.

Conforme Moro et al. (2012), espécies nativas são consideradas naturais da região em que vivem e espécies exóticas são aquelas que habitam locais além de sua distribuição natural, mediante interveção antrópica. As exóticas ainda podem ser divididas em naturalizadas, quando conseguem autoperpetuar sem dispersar-se para longe do local de introdução, e invasoras, quando conseguem autoperpetuar e dispersar-se para áreas distantes. As epífitas naturalizadas foram classificadas conforme Flora do Brasil 2020 (2017) e as exóticas invasoras de acordo com Portaria do Instituto Ambiental do Paraná no 59 de 2015.

A partir das categorias ecológicas propostas por Benzing (1990), fez-se o agrupamento das espécies, baseando-se no tempo de permanência destas sobre os forófitos, em, a) holoepífitas verdadeiras, plantas que em nunhum momento de sua vida mantêm contato com o solo; b) holoepífitas facultativas, podem se desenvolver tanto em árvores quanto no solo; c) epífitas acidentais, plantas que mesmo sem apresentar nenhuma adaptação para o hábito epifítico, podem crescer sobre um forófito; e d) hemiepífitas, plantas que apresentam o hábito epifítico em parte da vida, ou seja, iniciam ou terminam seu ciclo em contato com o solo.

As epífitas também foram classificadas de acordo com as síndromes de dispersão, tendo como base os critérios morfológicos descritos por van der Pijl (1982), sendo: a) anemocoria: utilizam o vento como agente dispersor; b) autocoria: plantas que realizam autodispersão de forma explosiva ou pela ação da gravidade; e c) zoocoria: quando diásporos são dispersos por animais.

\section{RESULTADOS E DISCUSSÃO}

O levantamento realizado na arborização urbana da cidade de Quinta do Sol, Paraná, possibilitou encontrar 40 espécies de forófitos que serviam de suporte para 61 espécies de epífitas vasculares, distribuídas em 21 famílias e 47 gêneros (Tabela 1). O grupo das Angiospermas foi o mais importante, representado por 18 famílias e 54 espécies $(88,5 \%$ das espécies encontradas) e o grupo das pteridófitas foi representado por três famílias e sete espécies ( $11,5 \%$ das espécies encontradas). 
Tabela 1. Lista de epífitas encontradas na arborização urbana da cidade de Quinta do Sol - Paraná, Brasil

Table 1. List of epiphytes found in the urban forestry of Quinta do Sol - Paraná, Brazil Continua...

\begin{tabular}{|c|c|c|c|c|}
\hline Família & Família/Espécie & $\begin{array}{l}\text { Categoria } \\
\text { ecológica }\end{array}$ & $\begin{array}{l}\text { Sindrome } \\
\text { dispersão }\end{array}$ & Origem \\
\hline Amaranthaceae & Amaranthus spinosus L. & EA & ANE & NTU \\
\hline \multirow{4}{*}{ Araceae } & Epipremnum pinnatum (L.) Engl. & HME & $\mathrm{ZOO}$ & EXO \\
\hline & Monstera deliciosa Liebm. & HME & ZOO & EXO \\
\hline & Philodendron bipinnatifidum Schott & HME & ZOO & NAT \\
\hline & Syngonium podophyllum Schott & HME & ZOO & EXO \\
\hline Araliaceae & Schefflera arboricola (Hayata) Merr. & EA & $\mathrm{ZOO}$ & $\mathrm{EXO}^{*}$ \\
\hline Arecaceae & Syagrus romanzoffiana (Cham.) Glassman & EA & $\mathrm{ZOO}$ & NAT \\
\hline \multirow{3}{*}{ Asteraceae } & Bidens pilosa $\mathrm{L}$. & EA & ZOO & NTU \\
\hline & Sonchus sp. & EA & ANE & NC \\
\hline & Sonchus oleraceus L. & EA & ANE & NAT \\
\hline Boraginaceae & Cordia americana (L.) Gottschling \& J.S.Mill. & EA & ANE & NAT \\
\hline \multirow{6}{*}{ Bromeliaceae } & Acanthostachys strobilacea (Schult. \& Schult.f.) Klotzsch & HV & ZO० & NAT \\
\hline & Aechmea distichantha Lem. & HF & ANE & NAT \\
\hline & Tillandsia Ioliacea Mart. ex Schult. \& Schult.f. & HV & ANE & NAT \\
\hline & Tillandsia pohliana Mez & HV & ANE & NAT \\
\hline & Tillandsia recurvata (L.) L. & HV & ANE & NAT \\
\hline & Tillandsia tricholepis Baker & HV & ANE & NAT \\
\hline \multirow{13}{*}{ Cactaceae } & Brasiliopuntia brasiliensis (Willd.) A.Berger & EA & ZOO & NAT \\
\hline & Cereus hildmannianus K.Schum. & EA & ZOO & NAT \\
\hline & Epiphyllum sp. & HV & ZOO & NC \\
\hline & Epiphyllum oxypetalum (DC.) Haw. & HV & ZOO & NTU \\
\hline & Epiphyllum phyllanthus (L.) Haw. & HV & ZOO & NAT \\
\hline & Hylocereus undatus (Haw.) Britton \& Rose & HV & ZOO & EXO \\
\hline & Lepismium cruciforme (Vell.) Miq. & HV & ZOO & NAT \\
\hline & Lepismium lumbricoides (Lem.) Barthlott & HV & ZO० & NAT \\
\hline & Lepismium warmingianum (K. Schum.) Barthlott & HV & $\mathrm{ZOO}$ & NAT \\
\hline & Opuntia ficus-indica (L.) Mill. & EA & ZOO & NTU \\
\hline & Rhipsalis sp. & HV & ZOO & NC \\
\hline & Schlumbergera truncata (Haw.) Moran. & HV & ZOO & NAT \\
\hline & Selenicereus anthonyanus (Alexander) D.R. Hunt. & HV & ZOO & EXO \\
\hline \multirow{2}{*}{ Commelinaceae } & Callisia cf. fragrans (Lindl.) Woodson. & EA & ANE & EXO \\
\hline & Tradescantia sp. & NC & ANE & NC \\
\hline Crassulaceae & Kalanchoe tubiflora Raym.-Hamet & EA & ANE & EXO \\
\hline Cyperaceae & Cyperus sp. & EA & ZOO & NC \\
\hline \multirow{2}{*}{ Moraceae } & Ficus sp. & HME & ZOO & NAT \\
\hline & Ficus cf. guaranitica Chodat & HME & ZOO & NAT \\
\hline \multirow{2}{*}{ Myrtaceae } & Eugenia uniflora L. & EA & $\mathrm{ZOO}$ & NAT \\
\hline & Psidium guajava L. & EA & ZOO & NTU* $^{*}$ \\
\hline Nephrolepidaceae & Nephrolepis sp. & HV & ANE & NC \\
\hline
\end{tabular}


...continuação

\begin{tabular}{|c|c|c|c|c|}
\hline Família & Família/Espécie & $\begin{array}{l}\text { Categoria } \\
\text { ecológica }\end{array}$ & $\begin{array}{l}\text { Sindrome } \\
\text { dispersão }\end{array}$ & Origem \\
\hline \multirow{11}{*}{ Orchidaceae } & Catasetum sp. & HV & ANE & NC \\
\hline & Dendrobium sp. & HV & ANE & EXO \\
\hline & Dendrobium nobile Lindl. & HV & ANE & EXO \\
\hline & Dendrobium thyrsiflorum Rchb.f. ex André & HV & ANE & EXO \\
\hline & Epidendrum sp. & $\mathrm{HF}$ & ANE & NC \\
\hline & Epidendrum denticulatum Barb.Rodr. & HF & ANE & NAT \\
\hline & Gomesa bifolia (Sims) M.W.Chase \& N.H.Williams & HV & ANE & NAT \\
\hline & Laelia sp. & HV & ANE & NC \\
\hline & Miltonia flavescens (Lindl.) Lindl. & HV & ANE & NAT \\
\hline & Phalaenopsis sp. & HV & ANE & EXO \\
\hline & Vanda teres (Roxb.) Lindl. & HF & ANE & EXO \\
\hline Piperaceae & Peperomia sp. & HV & ZOO & NAT \\
\hline Poaceae & Não identificada & EA & ANE & NC \\
\hline \multirow{5}{*}{ Polypodiaceae } & Microgramma squamulosa (Kaulf.) de la Sota & HV & ANE & NAT \\
\hline & Microgramma vacciniifolia (Langsd. \& Fisch.) Copel. & HV & ANE & NAT \\
\hline & Platycerum sp. & HV & ANE & EXO \\
\hline & Pleopeltis minima (Bory) J. Prado \& R.Y. Hirai & HV & ANE & NAT \\
\hline & Pleopeltis pleopeltifolia (Raddi) Alston & HV & ANE & NAT \\
\hline \multirow{2}{*}{ Portulacaceae } & Portulaca sp. & EA & NC & EXO \\
\hline & Talinum paniculatum (Jacq.) Gaertn. & EA & ANE & NAT \\
\hline Solanaceae & Solanum mauritianum Scop. & EA & ZOO & NAT \\
\hline Thelypteridaceae & Não identificada & EA & ANE & NC \\
\hline
\end{tabular}

Nota: $\mathbf{E A}=$ Epífita acidental; $\mathbf{H M E}=$ Hemiepífita; $\mathbf{H V}=$ Holoepífita verdadeira; $\mathbf{H F}=$ Holoepífita facultativa; $\mathbf{A N E}=$ Anemocoria; ZOO = Zoocoria; $\mathbf{N A T}=$ Nativa; $\mathbf{N T U}=$ Naturalizada; EXO $=$ Exótica $.{ }^{*}=$ Exótica invasora; $\mathbf{N C}=$ Não classificada.

As famílias Cactaceae e Orchidaceae apresentaram o maior número de espécies epifíticas $(21,3 \%$ e $18 \%$ respectivamente), seguidas por Bromeliaceae $(9,8 \%)$ e Polypodiaceae $(8,2 \%)$ (Figura 2). O resultado do presente estudo se difere de outros trabalhos pela frequência de espécies da família Cactaceae, onde sua representatividade encontra-se inferior à terceira colocação (BENZING, 1990; DETTKE; ORFRINI; MILANEZE-GUTIERRE, 2008; GERALDINO; CAXAMBU; SOUZA, 2010; KERSTEN, 2010; MANIA; MONTEIRO, 2010; BLUM; RODERJAN; GALVÃO, 2011; RITTER et al., 2014; DEVENS et al., 2015; BATAGHIN; BARROS; PIRES, 2017). 


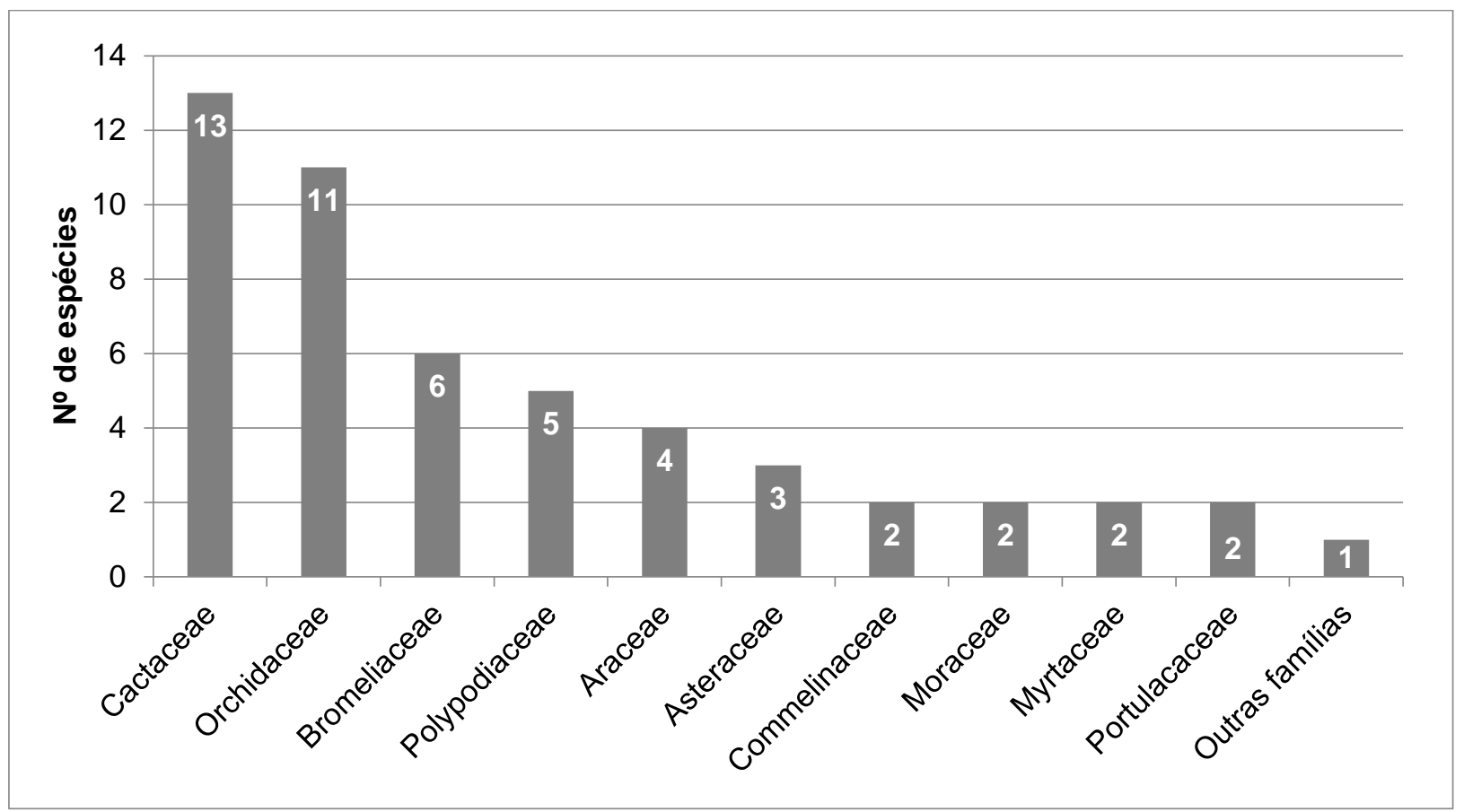

Figura 2. Espécies encontradas por família botânica na arborização urbana da cidade de Quinta do Sol Paraná, Brasil

Figure 2. Species found by botanical family in the urban forestry of Quinta do Sol - Paraná, Brazil

A classificação segundo as categorias ecológicas apontou maior representatividade das espécies caracterizadas como holoepífitas verdadeiras, perfazendo 49,2\%, logo em seguida encontram-se as espécies de epífitas acidentais, com 32,8\% (Figura 3). O maior número de holoepífitas verdadeiras é da família Cactaceae, seguido por Orchidaceae, Bromeliaceae e Polypodiaceae. As epífitas acidentais apresentam-se muito diversas, sendo representados por 14 famílias.

Os trabalhos realizados na arborização urbana por Ritter et al. (2014) e Devens et al. (2015) também demonstram maior ocorrência de holoepífitas verdadeiras, entretanto, somente Ritter et al. (2014) encontrou epífitas acidentais com a segunda maior ocorrência. Já em estudos realizados em fragmentos florestais próximos a zona urbana, notou-se a predominância de holoepífitas verdadeiras, mas espécies acidentais foram pouco representativas (DETTKE; ORFRINI; MILANEZE-GUTIERRE, 2008; GERALDINO; CAXAMBU; SOUZA, 2010).

Analisando as epífitas encontradas quanto à origem, 29 espécies eram nativas, 15 exóticas, 12 não foram classificadas em função da impossibilidade de se proceder à identificação e cinco espécies eram naturalizadas (Figura 3). 


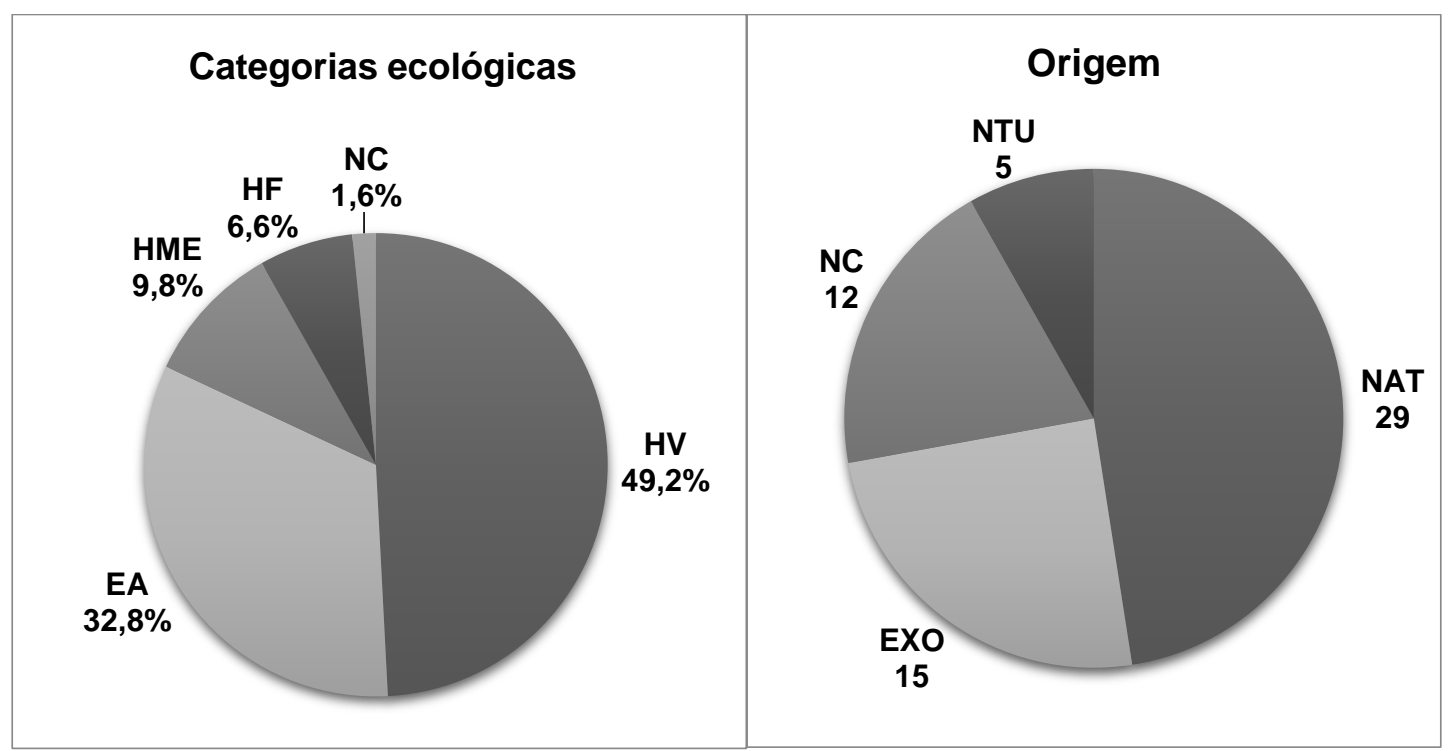

Nota: $\mathbf{E A}=$ Epífita acidental; $\mathbf{H M E}=$ Hemiepífita; $\mathbf{H V}=$ Holoepífita verdadeira; $\mathbf{H F}=$ Holoepífita facultativa; $\mathbf{N A T}=$ Nativa; $\mathbf{N T U}=$ Naturalizada; $\mathbf{E X O}=$ Exótica; $\mathbf{N C}=$ Não classificada .

Figura 3. Representação das categorias ecológicas e origem das espécies de epífitas encontradas na arborização urbana da cidade de Quinta do Sol - Paraná, Brasil

Figure 3. Ecological categories representation and epiphytes species origin found in the urban forestry of Quinta do Sol - Paraná, Brazil

Das classificadas como exóticas, Schefflera arboricola (Hayata) Merr. (cheflerapequena) e Psidium guajava L. (goiaba), ambas encontradas como epífitas acidentais, estavam listadas como plantas exóticas invasoras do estado do Paraná de acordo com o Anexo I da Portaria do Instituto Ambiental do Paraná (IAP) no 59 de 2015.

Excetuando-se as epífitas não classificadas quanto à origem, a representatividade das espécies exóticas foi de 30,6\%, enquanto que nos levantamentos de Ritter et al. (2014) e Devens et al. (2015), o resultado foi de $20 \%$ e $18 \%$ respectivamente, não havendo registros de espécies exóticas invasoras. Kersten e Kuniyoshi (2009) avaliaram a composição e distribuição dos epífitos vasculares em ambientes florestais, observando 1,39\% de epífitas exóticas, declarando assim que a presença dessas indicou perturbações nos ambientes. As cidades são consideradas áreas de alta perturbação, devido às intervenções humanas, como exemplo, inserção de epífitas de maneira cultivada, o que propicia o aparecimento de espécies exóticas.

Quanto à síndrome de dispersão, obteve-se 52,5\% de espécies anemocóricas, 40\% de zoocóricas e 6,5\% não puderam ser classificadas, devido à impossibilidade de proceder à identificação destas espécies em nível de gênero. Considerando que Devens et al. (2015) encontrou apenas 18,2\% de espécies zoocóricas, suscita-se a hipótese de que o alto valor obtido nesse estudo tem relação com a dispersão realizada pelos munícipes, através do cultivo de espécimes epifíticos.

Estudos em áreas mais preservadas confirmam a predominância da dispersão anemocórica, devido principalmente à alta representatividade de Orchidaceae. A presença de 
indivíduos zoocóricos é considerada relevante, dado que muitas espécies animais dependem deste recurso alimentar ao longo do ano, tornando a cidade uma mantenedora da diversidade faunística (DETTKE; ORFRINI; MILANEZE-GUTIERRE, 2008).

A grande ocorrência das epífitas pertencentes à família Cactaceae pode estar relacionada à importância dos elementos da paisagem na cultura da população local. Essa situação foi evidenciada pela presença de diversos indivíduos na arborização urbana que foram inseridos pelos moradores, a exemplo, espécimes de Selenicereus anthonyanus (Alexander) D.R. Hunt (cacto-sianinha), Hylocereus undatus (Haw.) Britton \& Rose (pitaya-vermelha) e Dendrobium nobile Lindl (olho-de-boneca), caracterizadas como exóticas e encontradas em locais com intensa visitação humana (DETTKE; ORFRINI; MILANEZE-GUTIERRE, 2008). Os indivíduos de D. nobile foram os mais recorrentes, corroborando com Vichiato et al. (2007), que aponta como uma espécie muito popular no Brasil, com destaque no mercado de plantas de corte e de vaso.

As condições encontradas nas áreas urbanizadas também influenciaram a ocorrência das espécies da família Cactaceae. O ambiente urbano não proporciona a manutenção de um microclima com umidade e temperatura favorável para o desenvolvimento de todas as espécies, tornando a Cactaceae mais representativa devido a sua capacidade de sobreviver a condições de estresse hídrico e sua interação com a fauna (BATAGHIN; BARROS; PIRES, 2017).

Durante o levantamento também foram encontrados espécimes de Phoradendron quadrangulare (Kunth) Griseb. (erva-de-passarinho), associados de forma recorrente a forófitos da família Bignoniaceae. Trata-se de uma espécie nativa, hemiparasita e dispersada por aves. No estudo de Cazetta e Galetti (2007) foi verificada a mesma relação, onde indivíduos do gênero Phoradendron foram encontrados sobre forófitos de Handroanthus ochraceus (Cham.) Mattos (ipê-do-cerrado), indicando que a ocorrência e frequência das infestações podem estar associadas às atividades da avifauna e das características do hospedeiro.

O número máximo de espécies encontradas em uma única árvore foi 11 e o mínimo um, onde a espécie mais abundante foi Tillandsia recurvata (L.) L. (tilândsia). A família Bromeliaceae é amplamente distribuída, possui alta variabilidade genética e diversas espécies adaptadas à vida epifítica, como os indivíduos do gênero Tillandsia, que são formados por representantes com uma organização estrutural e química altamente especializada, podendo sobreviver aos mais diferentes tipos de ambientes extremos (VASCONCELOS et al., 2013).

Bataghin, Barros e Pires (2010) encontraram indivíduos de T. recurvata em 99\% dos forófitos e em $90 \%$ dos estratos de remanescente florestal isolado e alterado, já em borda de floresta avançada à espécie se mostrou a mais importante, entretanto, sua presença foi registrada em apenas $64 \%$ dos forófitos e em $32 \%$ dos estratos. No interior de floresta 
avançada os mesmos autores encontraram reduzida representatividade da espécie, o que denota a sua maior tendência em habitar ambientes alterados.

Tillandsia recurvata é uma epífita que sofreu modificações metabólicas ao longo da sua evolução, permitindo que sobrevivesse com a mínima quantidade de água dispersa na atmosfera sob a forma de vapor, o que a tornou uma espécie cosmopolita adaptada a um clima de habitats áridos (VASCONCELOS et al., 2013). Todas essas características de adaptabilidade justificam sua ampla dispersão no ambiente urbano, propiciando a colonização de forófitos em diversos estágios de desenvolvimento. Em Quinta do Sol, foi verificada frequentemente a presença de $T$. recurvata de maneira isolada em forófitos jovens e até mesmo em infraestruturas como muros, postes e fiação elétrica.

Se tratando dos trabalhos já realizados considerando as epífitas em meio urbano, Quinta do Sol, Farol e Luiziana se encontram na mesorregião centro ocidental do Paraná, possuem população inferior a oito mil habitantes e apresentam taxa de arborização de vias públicas variando de 90,5\% a 97\% (IBGE, 2010). São municípios próximos e considerados de pequeno porte, que, mesmo apresentando taxas de arborização similares, o número de espécies epifíticas de Quinta do Sol apresentou-se aproximadamente seis vezes superior ao encontrado nos levantamentos realizados por Devens et al. (2015) e Ritter et al. (2014).

\section{CONCLUSÕES}

O presente estudo registra uma das maiores riquezas de epífitas vasculares já encontradas, até o momento, em arborização urbana no estado do Paraná. O maior número de espécies registradas são de Cactaceae. Por outro lado, a espécie com maior abundância foi Tillandsia recurvata (Bromeliaceae), demonstrando ampla dispersão no ambiente urbano, devido a sua capacidade de adaptação e dispersão anemocórica, que possibilita colonizar forófitos em diversos estágios de desenvolvimento.

Evidenciou-se grande número de epífitas exóticas, por conta do alto grau de perturbação do ambiente urbano, ocasionado principalmente pela dispersão realizada pelos munícipes visando ornamentação. A alta diversidade de espécies de Cactaceae também está associada a essas perturbações.

Mesmo com a predominância da dispersão anemocórica, observou-se elevada representatividade da síndrome de dispersão zoocórica, ficando evidente, a necessidade de se estudar ainda mais essa sinúsia no meio urbano e a importância da arborização urbana como mantenedora da diversidade faunística. 


\section{AGRADECIMENTOS}

Os autores agradecem o auxílio prestado durante as coletas ao servidor Edemilson Luiz Siqueira e aos alunos Leonardo de Souza Molina e Rebeca Melo Lima, do curso de graduação em Engenharia Ambiental da Universidade Tecnológica Federal do Paraná (UTFPR), Câmpus Campo Mourão, a acadêmica também de Engenharia Ambiental Ana Clara de Oliveira e a pesquisadora Greta Aline Dettke.

\section{REFERÊNCIAS}

ALVARES, C. A.; STAPE, J. L.; SENTELHAS, P. C.; GONÇALVES, J. L de M.; SPAROVEK, G. Köppen's climate classification map for Brazil. Meteorologische Zeitschrift, Stuttgart, v. 22, n. 6, p. 711-728, 2013.

APG IV. An update of the Angiosperm Phylogeny Group classification for the orders and families of flowering plants: APG IV. Botanical Journal of the Linnean Society, London, $v$. 181, n. 1, p. 1-20, 2016.

BATAGHIN, F. A.; BARROS, F. de; PIRES, J. S. R. Distribuição da comunidade de epífitas vasculares em sítios sob diferentes graus de perturbação na Floresta Nacional de Ipanema, São Paulo, Brasil. Revista Brasileira de Botânica, São Paulo, v. 33, n. 3, p. 501-512, 2010.

BATAGHIN, F. A.; BARROS, F. de; PIRES, J. S. R. Epífitas vasculares da Estação Ecológica Barreiro Rico, Anhembi, SP, Brasil: diversidade, abundância e estratificação vertical. Hoehnea, São Paulo, v. 44, n. 2, p. 172-183, 2017.

BENZING, D. H. Vascular epiphytes. Cambridge: Cambridge University Press, 1990. 354p.

BLUM, C. T.; RODERJAN, C. V.; GALVÃO, F. Composição florística e distribuição altitudinal de epífitas vasculares da Floresta Ombrófila Densa na Serra da Prata, Morretes, Paraná, Brasil.

Biota Neotropica, Campinas, v. 11, n. 4, p. 141-159, 2011.

CAZETTA, E.; GALETTI, M. Frugivoria e especificidade por hospedeiros na erva-de-passarinho Phoradendron rubrum (L.) Griseb. (Viscaceae). Revista Brasileira de Botânica, São Paulo, v. 30, n. 2, p. 345-351, 2007.

DETTKE, G. A.; ORFRINI, A. C.; MILANEZE-GUTIERRE, M. A. Composição florística e distribuição de epífitas vasculares em um remanescente alterado de Floresta Estacional Semidecidual no Paraná, Brasil. Rodriguésia, Rio de Janeiro, v. 59, n. 4, p. 859-872, 2008.

DEVENS, K. U.; GERALDINI, A. P. B.; AMADEO, R. M.; CAXAMBU, M. G.; MAGNONI, P. H. J. Levantamento de epífitas na arborização urbana do município de Luiziana - Paraná. Revista da Sociedade Brasileira de Arborização Urbana, Piracicaba, v. 10, n. 4, p. 1-11, 2015.

FLORA DO BRASIL 2020 EM CONSTRUÇÃO. Jardim Botânico do Rio de Janeiro. Disponível em: < http://floradobrasil.jbrj.gov.br/ > Acesso em: 03 jul. 2017. 
GERALDINO, H. C. L.; CAXAMBU, M. G.; SOUZA, D. C. Composição florística e estrutura da comunidade de epífitas vasculares em uma área de ecótono em Campo Mourão, PR, Brasil.

Acta Botanica Brasilica, São Paulo, v. 24, n. 2, p. 469-482, 2010.

INSTITUTO BRASILEIRO DE GEOGRAFIA E ESTATÍSTICA (IBGE). Manual técnico da vegetação brasileira. Rio de Janeiro: IBGE, 2012. 271p.

INSTITUTO BRASILEIRO DE GEOGRAFIA E ESTATÍSICA (IBGE). Cidades. 2010. Disponível em: <http://www.cidades.ibge.gov.br/xtras/uf.php?lang=\&coduf=41\&search=parana $>$ Acesso em: 04 jun. 2017.

KERSTEN, R. de A. Epífitas vasculares - Histórico, participação taxonômica e aspectos relevantes, com ênfase na Mata Atlântica. Hoehnea, São Paulo, v. 37, n. 1, p. 9-38, 2010.

KERSTEN, R. de A.; KUNIYOSHI, Y. S. Conservação das florestas na Bacia do Alto Iguaçu, Paraná - Avaliação da comunidade de epífitas vasculares em diferentes estágios serais.

Floresta, Curitiba, v. 39, n. 1, p. 51-66, 2009.

MANIA, L. F.; MONTEIRO, R. Florística e ecologia de epífitas vasculares em um fragmento de floresta de restinga, Ubatuba, SP, Brasil. Rodriguésia, Rio de Janeiro, v. 61, n. 4, p. 705-713, 2010.

MEIRA, G. R. N.; TEIXEIRA, G. G. M.; VENTURIN, P. R. F.; GOTTSTEIN, P.; CAXAMBU, M. G. Avaliação quali-quantitativa de espécies arbóreas no perímetro urbano da cidade de Corumbataí do Sul - PR. Revista da Sociedade Brasileira de Arborização Urbana, Piracicaba, v. 10, n. 4, p. 36-49, 2015.

MORO, M. F.; SOUZA, V. C.; OLIVEIRA-FILHO, A. T. de; QUEIROZ, L. P. de; FRAGA, C. N. de; RODAL, M. J. N.; ARAÚJO, F. S. de; MARTINS, F. R. Alienígenas na sala: o que fazer com espécies exóticas em trabalhos de taxonomia, florística e fitossociologia? Acta Botanica Brasilica, São Paulo, v. 26, n. 4, p. 991-999, 2012.

PPG I. A community-derived classification for extant lycophytes and ferns. Journal of Systematics and Evolution, China, v. 54, n. 6, p. 563-603, 2016.

RITTER, C. M.; SANTOS, F. R.; CRESPÃO, L. M. P.; ARDENGUI, T. C.; CAXAMBU, M. G. Levantamento de epífitas presentes na arborização urbana no município de Farol, PR, Brasil. Revista da Sociedade Brasileira de Arborização Urbana, Piracicaba, v. 9, n. 3, p. 18-28, 2014.

ROSSATO, D. R. ; TSUBOY, M. S. F. ; FREI, F. Arborização urbana na cidade de Assis-SP: uma abordagem quantitativa. Revista da Sociedade Brasileira de Arborização Urbana, Piracicaba, v. 3, n. 3, p. 1-16, 2008.

VAN DER PIJL, L. Principles of Dispersal in Higher Plants. Berlim: Springer-Verlag Berlin Heidelberg, 1982. $215 \mathrm{p}$.

VASCONCELOS, A. L. de; VASCONCELOS, A. L. de; XIMENES, E. A.; RANDAU, K. P. Tillandsia recurvata L. (Bromeliaceae): aspectos farmacognósticos. Revista Ciências Farmacêuticas Básica Aplicada, Araraquara, v. 34, n. 2, p. 151-159, 2013.

VICHIATO, M. R. de M.; VICHIATO, M.; CASTRO, D. M. de; DUTRA, L. F.; PASQUAL, M. Alongamento de plantas de Dendrobium nobile Lindl. com pulverização de ácido giberélico. Ciência e Agrotecnologia, Lavras, v. 31, n. 1, p. 16-20, 2007. 